九州大学学術情報リポジトリ

Kyushu University Institutional Repository

\title{
The true origin of ductile fracture in aluminium alloys
}

Toda, Hiroyuki

Department of Mechanical Engineering, Kyushu University

Oogo, Hideyuki

Department of Mechanical Engineering, Toyohashi University of Technology

Horikawa, Ke itaro

Department of Mechanical Science and Bioengineering, Graduate School of Engineering Science, Osaka University

Uesugi, Kentaro

Japan Synchrotron Radiation Research Institute

他

ht tp://hdl. hand le. net/2324/1800894

出版情報: Metallurgical and Materials Transactions A. 45 (2)，pp.765-776，2014-02. ASM International

バージョン :

権利関係 : 


\section{The true origin of ductile fracture in aluminium alloys}

Hiroyuki Toda*a, Hideyuki Oogo ${ }^{\mathrm{b}}$, Keitaro Horikawac ${ }^{\mathrm{c}}$, Kentaro Uesugi ${ }^{\mathrm{d}}$, Akihisa Takeuchi $^{\mathrm{d}}$, Yoshio Suzuki ${ }^{\mathrm{d}}$, Mitsuru Nakazawa ${ }^{\mathrm{e}}$, Yoshimitsu Aoki ${ }^{\mathrm{e}}$ and Masakazu Kobayashi ${ }^{\mathrm{b}}$

${ }^{\text {a }}$ Department of Mechanical Engineering, Kyushu University, 744, Motooka, Nishi-ward, Fukuoka, FUKUOKA, 819-0395, Japan (e-mail: toda@mech.kyushu-u.ac.jp, tel: +81-928023246, fax: +81-928020001 (H. Toda))

b Department of Mechanical Engineering, Toyohashi University of Technology, 1-1, Hibarigaoka, Tempaku, Toyohashi, Aichi 441-8580, Japan

c Department of Mechanical Science and Bioengineering, Graduate School of Engineering Science, Osaka University, 1-3, Machikaneyama, Toyonaka, Osaka 560-8531, Japan

d Japan Synchrotron Radiation Research Institute, 1-1-1, Kouto, Mikazuki-cho, Sayo-gun, Hyogo 679-5198, Japan

e Electronics \& Electrical Engineering, Keio University, 3-14-1, Hiyoshi, Kohoku-ku, Yokohama, Kanagawa 223-8522, Japan 


\begin{abstract}
It has generally been assumed that metals usually fail as a result of microvoid nucleation induced by particle fracture. Here we concentrate on high-density micropores filled with hydrogen in aluminium, whose existence has been largely overlooked until quite recently. These micropores exhibit premature growth under external loading, thereby inducing ductile fracture, whereas the particle fracture mechanism operates only incidentally. Conclusive evidence of a micropore mechanism is provided by the observation of an instantaneous release of gas at failure. We can therefore conclude that the growth of micropores dominates ductile fracture. Since the material we used has a standard pore density, we can assume that an identical fracture mechanism operates in other aluminium alloys. This finding suggests that intense heat treatment, which is generally believed to enhance the mechanical properties through homogenisation, may have entirely the opposite effect. This revelation will have a major impact on the engineering design of metals.
\end{abstract}

Keywords: X-ray tomography; hydrogen; micropore; ductile fracture; aluminium alloy 


\section{Introduction and background}

Monotonic fracture in metals begins with the initiation of microvoids induced by the damage initiation at particles [1]. The fracture is then terminated by the formation of a new surface, which is called a fracture surface, through the growth [2] and coalescence [3] of the microvoids. The process, which is called ductile fracture, is common and occurs in almost all structural metallic materials [4,5]. A great deal of work has been undertaken to obtain a complete understanding of this process from various viewpoints ranging from the nanoscopic level, where the dislocation theory applies, to the meso- and macroscopic levels, where continuum mechanics is required. Today, this process is taken for granted in our understanding of the fundamental strength of materials, and appears in every textbook dealing with the field $[4,5]$. It would not be an exaggeration to say that modern structural materials have been developed by controlling material characteristics, taking into account the above-mentioned fracture mechanism [6].

In terms of the damage initiation at particles, it is well-known that ordinary modes of damage initiation involve either fracture of secondary-phase particles dispersed in the metals or debonding at the metal/particle interface [1]. Although microvoids can nucleate at slip band intersections in titanium alloys and Incoloy [7], this is not typical microvoid nucleation mechanism. The damage initiation at particles has been extensively investigated in both experimental and modelling studies to date. It has been reported that microvoid nucleation is strongly influenced by particle radius, particle shape and particle volume fraction [7]. According to Gangulee et al., particle fracture increases with $d^{1 / 2} / f^{1 / 3}$, where $d$ is particle diameter and $f$ is particle volume 
fraction. Experimental evidence also suggests that particle damage occurs first at larger particles among dispersed particles that usually have a certain amount of distribution in particle size $[8,9]$. Mechanical properties of materials have therefore been assumed to be affected by these parameters. For example, some theoretical approaches show that tensile ductility increases with decreasing particle size [10] and volume fraction ${ }^{7}$, which has also been verified experimentally [11]. In light of these insights, industrial homogenisation and solution heat treatments are usually undertaken to reduce relatively coarse particles by exposing materials at a sufficiently high temperature for a sufficiently long time wherever possible.

In this connection, recently developed high-resolution X-ray microtomography $[12,13]$ has revealed the existence of high-density micropores that are formed in almost all aluminium alloys by the precipitation of molecular hydrogen[14,15,16]. In general, the hydrogen content in aluminium alloys is $3-4$ orders of magnitude larger than hydrogen solubility, due mainly to the existence of a hydrogen solubility gap at the melting temperature of aluminium. The supersaturated hydrogen cannot be easily released due to the presence of a surface oxide layer. It has been revealed by the present authors that excess hydrogen in solid aluminium is predominantly partitioned as molecular hydrogen gas in micropores [15]. The occupancies of other trap sites, such as normal interstitial lattice sites, solute atoms, dislocations and grain boundaries, are elevated with further increases in hydrogen concentration [15]. The number of such pores reaches about 8,000 - 70,000 per $1 \mathrm{~mm}^{3}$ even in wrought aluminium alloys [17]. It has been reported that secondary porosity in aluminum alloys does not close through subsequent extensive plastic deformation, such as that caused by hot and cold rolling[18,19]. Nevertheless, the high-density micropores have remained unnoticed in 
conventional cross-sectional observations, mainly because they easily fill with the abrasion powders when samples are cut and polished. The discovery of their existence has evoked a sense of wonder in materials scientists and engineers, who have usually engaged in surface and cross-sectional observations.

It has been reported that the mechanical properties of aluminium alloys are sometimes sensitive to the presence of micropores. For example, large variability in mechanical properties such as ductility, strength and fatigue characteristics has usually been attributed to the existence of high density micropores in cast alloys[17,20,21]. It has also been reported that tensile strength decreases rapidly when the volume fraction of micropores increases up to $0.5-1 \%$ [22]. It seems that the mechanisms for such rapid decrease in tensile strength with a limited amount of micropores have not been fully clarified. Recently, it has been revealed that micropores are associated with ductile fracture mechanism in some wrought aluminium alloys [22,23]. According to 3D/4D (i.e., time axis and Euclidean space) observations, micropores began to expand from an early loading stage, while the above-mentioned particle damage was observed after plastic strain had accumulated. It has therefore been concluded that hydrogen micropores contribute to some extent to ductile fracture. Since micropores are directly formed on dispersion particles as the result of heterogeneous nucleation during solidification or the initial stage of heat treatment [15], it is reasonable to assume that micropores can grow under tension before microvoids caused by particle damage are initiated.

In the present study, we examine this hypothesis by employing high-resolution 4D observations combined with the recently developed microstructural tracking technique $[19,24,25]$. A detailed examination of the 4D characteristics of micropore 
growth is utilised to discuss the contributions of micropores to ductile fracture. This study also proposes a 4D image analysis method to correlate fracture surface to fracture origins embedded in materials before loading. This procedure has clear advantages over the previous simple observations because it provides unique possibilities for detecting fracture origins in a quantitative manner.

\section{Experimental methods}

\subsection{Sample preparation}

The material used was an AA2024 aluminium alloy with a high tolerance to damage, which is employed to fabricate structural members for aircraft. It was re-melted in a vacuum (about $1 \mathrm{~Pa}$ ) and then cast into an iron mould in the laboratory. This alloy is hereinafter called material LH to indicate its low hydrogen content. The same alloy was also melted in ambient laboratory air (hereinafter called material $\mathrm{HH}$ ). The vacuum fusion method was utilized to measure the total hydrogen content of each material. The alloy cast had a chemical composition of $4.447 \mathrm{Cu}, 1.462 \mathrm{Mg}, 0.452 \mathrm{Mn}, 0.150 \mathrm{Zn}$, 0.170 Fe, $0.047 \mathrm{Si}, 0.022 \mathrm{Ti}, 0.012 \mathrm{Cr}, 0.006 \mathrm{Zr}, 0.003 \mathrm{~Pb}, 0.003 \mathrm{Ni}$, and balance Al in mass $\%$.

The ingots were homogenised at $673 \mathrm{~K}$ for $28.8 \mathrm{ks}$, hot-rolled at $673 \mathrm{~K}$ by $50 \%$ and cold-rolled by $50 \%$ before applying a solution treatment at $768 \mathrm{~K}$ for $7.2 \mathrm{ks}$ and an ageing treatment at $533 \mathrm{~K}$ for $86.4 \mathrm{ks}$. Small I-shaped specimens (typically 0.6 (Width: $W) \times 0.6$ (Thickness: $B) \times 11$ (Length: $L) \mathrm{mm}$ ) for tomographic observation were carefully machined using an electrodischarge machine wire eroder so that tensile load is applied in the L-T orientation. Plate specimens for hydrogen measurement, with 
gauge section of $5(W) \times 1(B) \times 10(L) \mathrm{mm}$, were also prepared.

\subsection{Tomographic imaging}

A high-resolution X-ray CT experiment was performed using the X-ray imaging beamline, BL20XU, of the Japanese synchrotron radiation facility, SPring-8. A material test rig specially designed for X-ray CT was positioned approximately $242 \mathrm{~m}$ from the X-ray source. A monochromatic X-ray beam with a photon energy of $20 \mathrm{keV}$ generated by a liquid nitrogen-cooled Si (111) double crystal monochromator was used. An image detector consisted of a cooled $4000(\mathrm{H}) \times 2624(\mathrm{~V})$ element CCD camera (effective pixel size of the camera: $5.9 \mu \mathrm{m}$ ), which was used in $2 \times 2$ binning mode, a single crystal scintillator $\left(\mathrm{Lu}_{2} \mathrm{SiO}_{5}: \mathrm{Ce}\right)$ and a lens $(\times 20)$. The image detector was positioned $55 \mathrm{~mm}$ behind the sample, thereby making the imaging system sensitive to phase modulation. The in-situ loading stage allowed the specimen to be scanned under monotonic tensile loading. The first tomography scan was performed without loading, and the subsequent 12 and 9 scans were performed during loading for materials LH and HH, respectively. Fractured specimens were also scanned. In total, 1500 radiographs, scanning 180 degrees, were obtained in 0.12-degree increments. The entire cross-section of the specimen and a region about $622 \mu \mathrm{m}$ high were captured on the CCD camera. Image slices were reconstructed from a series of projections based on the conventional filtered backprojection algorithm. An isotropic voxel with a $0.5 \mu \mathrm{m}$ edge was achieved in the reconstructed slices. The grey value in each dataset was calibrated such that the linear absorption coefficient of $0 \sim 50 \mathrm{~cm}^{-1}$ fell within an 8-bit gray scale range between 0 and 255 . 


\subsection{Image analysis procedure}

To estimate the volume of each micropore at sub-voxel accuracy, pentagonal facetted iso-intensity surfaces were computed from the volumetric data set using the conventional Marching Cubes algorithm. A threshold value for obtaining binary images was chosen as 13 and 190 for micropores and particles, respectively. To suppress inaccuracies originating from image noise, only micropores over 23.168 voxels in volume were counted as micropores and particles in the quantitative analysis. Volume, $V$, surface area, $A$, and the centre of gravity are measured in the tomographic images. The equivalent diameter for a sphere of equal volume, and the sphericity, were defined as follows;

$$
\begin{aligned}
& \bar{d}=2 \sqrt[3]{3 V / 4 \pi} \\
& S_{p}=\sqrt[3]{36 \pi V^{2} / A}
\end{aligned}
$$

Precise image registration was then performed before the particles and micropores were tracked, using a transformation matrix, which minimizes the sum of the distances between identical microstructural features captured at neighbouring scan steps. The particles and micropores were tracked throughout tensile loading by employing the matching parameter method with the modified spring model $[24,25]$. Coefficients $\alpha, \beta$ and $\gamma$ in the matching probability parameter used in reference [24] and [25] were determined as $0.4,0.3$ and 0.3 , respectively, after systematically searching for the optimum condition in a preliminary trial. In the preliminary trial, 100 particles or micropores were randomly selected in each condition in order to search the optimum condition with a success ratio close to $100 \%$. The coefficient values were varied at 0.1 intervals between 0 and 1 . Tracking errors for all the 100 particles or micropores were subjectively checked in 3D images in each condition. 
2.4 Real-time measurement of hydrogen desorption during tensile tests

Tensile tests were performed in-situ in an ultra-high vacuum chamber equipped with a quadrupole mass spectrometer and a turbomolecular pump, monitoring the partial pressure of hydrogen outgassing from a specimen. Specimens were subjected to tension until fracture at room temperature. Hydrogen desorption from the specimens was detected at 2.4 ms intervals for five seconds around the moment of fracture, and at $100 \mathrm{~ms}$ for the rest of the tensile deformation.

\section{Damage and fracture behaviour during tensile loading}

\subsection{Microstructural features of the materials used}

The total hydrogen content, which is expressed as the equivalent volume of hydrogen gas at $0{ }^{\circ} \mathrm{C}$ and $1 \mathrm{~atm}$ per $100 \mathrm{~g}$ of aluminium, was 0.48 and $0.72 \mathrm{~cm}^{3}$ per 100 g of $\mathrm{Al}$ for materials $\mathrm{LH}$ and $\mathrm{HH}$, respectively. The total hydrogen content for material LH falls within the reported hydrogen content range of about 0.11 to $0.60 \mathrm{~cm}^{3}$ per $100 \mathrm{~g}$ Al for ordinary wrought aluminium alloys [26], while that of material $\mathrm{HH}$ is slightly higher than the range. 3D observations showed that the two materials contained almost spherical micropores (Fig. 1 (b)) with relatively narrow size distributions, centred at 2.5 $\mu \mathrm{m}$ as shown in Fig. 1 (a). Average micropore diameter is about 2.5 and $2.8 \mu \mathrm{m}$, and the number density of micropores is 156,300 and $163,700 / \mathrm{mm}^{3}$, for materials $\mathrm{LH}$ and $\mathrm{HH}$, respectively. The reason why the average micropore diameter is similar between the two materials, in spite of the roughly $50 \%$ difference in total hydrogen content, is that if Ostwald ripening dominates, average diameter is independent of total hydrogen content [15]. Average micropore size has been reported for several kinds of wrought aluminium 
alloys using high-resolution X-ray microtomography. Average micropore size for AA2024, AA5154, AA6061, AA7475 aluminium alloys and Al-5.5 mol. \% Mg alloy is reported to be 7.2 [14] /4.3 [22], 5.3 [23], 2.62 [17], 3.40 [17] and 3.5-3.6 [15] $\mu \mathrm{m}$, respectively, suggesting that the average micropore diameter of the materials used in the present study is relatively small. In contrast to the huge number of pores, the pore volume fraction is only 0.19 and $0.27 \%$ for materials $\mathrm{LH}$ and $\mathrm{HH}$, respectively. The pore volume fraction values for the present materials were comparable to the reported values of $0.254 \%$ [14] and $0.20 \%$ [22] for commercial 2024 aluminium alloys that have been supplied from manufacturers. Under the thermal equilibrium assumption that the surface tension of a metal is balanced by an opposing gas pressure inside each pore [15], about $71(\mathrm{LH})$ to $63(\mathrm{HH}) \%$ of the solute hydrogen is estimated to be trapped in micropores.

The shape and size of dispersion particles are shown in Fig. 1 (c) and (d). The number density of dispersion particles is 670,800 and $537,800 / \mathrm{mm}^{3}$ for materials $\mathrm{LH}$ and $\mathrm{HH}$, respectively. It can be inferred that the number of dispersion particles is sufficient to derive internal local displacement fields in high density. Almost all the hydrogen micropores were adjacent to dispersion particles, as shown in Figs. 2 and 3. This is because dispersion particles provide energetically favourable sites for the heterogeneous nucleation of hydrogen when supersaturated atomic hydrogen is precipitated as molecules [15]. It therefore implies that micropores are formed on dispersion particles simultaneously with hydrogen precipitation.

3.2 Micropore growth and coalescence behaviours during loading

Since micropore growth and coalescence behaviours, and their overall 
contribution to the ductile fracture, are not apparently different between materials LH and $\mathrm{HH}$, only the results for material $\mathrm{HH}$ are introduced in this section due to limitations of space.

Figure 4 shows a stress-strain curve in which the 10 loading steps for 3D observations are indicated. The vertical lines above the loading step numbers in Fig. 4 indicate relaxation behaviour of the material during the 20-minute ageing before each scan, which was performed to suppress the occurrence of blurring caused by the relaxation behaviour during scanning.

Figure 2 also shows the 3D distribution of dispersion particles (highlighted in light blue), micropores and microvoids (both highlighted in red) within part of a rendered volume in material HH. A large number of particles, which exhibit inhomogeneous distribution, are observed in the specimen. Although it is not so obvious at this magnification, micropore growth and/or damage initiation and growth is gradually observed from the early loading stages. It is noteworthy that although considerable damage had accumulated just before the final fracture (Fig. 2 (g)) from a macroscopic point of view, almost no micropores and/or damage is observed in some areas in Fig. 2 (g) in which no particles are locally observed in the initial image shown in Fig. 2 (a). This implies that damage is inevitably associated with either particle fracture or micropore growth that is adjacent to particles. The final fracture surface exhibits the cup-and-cone pattern with the final shear of the specimen, which is typical of the ductile fracture in aluminium alloys. In order to investigate the micropore growth and coalescence behaviours during loading in more detail, the largest crack observed in the last loading step, which can be identified around the central part of Fig. 2 (g), has been extracted in Fig. 5 (j). Micropores and microvoids that have coalesced into the 
largest crack have been extracted in Fig. 5 (a) - (i). Only pre-existing hydrogen micropores are visualised in Fig. 5 (a), while the other pores that were initiated during the subsequent loading steps are microvoids due to particle fracture. The extracted micropores and microvoids have been identified by tracking them in reverse chronological order. It can be confirmed in Fig. 5 (b) that pre-existing hydrogen micropores had already begun to grow before the 1st loading step, which is well before the maximum load; and the earliest coalescence of the micropores was already observed at the 1st loading step. At the 2nd loading step, which almost corresponds to the maximum load at which localised deformation usually begins, newly initiated microvoids were observed, as indicated by blue arrows in Fig. 5 (c). There existed a few micropore/microvoid groups, labelled as A - E in Fig. 5 (c) and (f). Micropores/microvoids in each group were gradually coalesced before the 5 th -7 th loading steps. The micropore/microvoid groups were then interconnected through the initiation of intervening microvoids. For example, groups A, B and D were merged into a relatively large crack at the 6th loading step. Rapid growth of intervening microvoids is clearly shown in regions $G$ and $F$ in Fig. 5 (i). It can be inferred that stress concentration and the generation of a tri-axial stress state provide sufficient driving force for the growth of intervening microvoids, resulting in the formation of the large crack located in the central region of the fracture surface. The six blue solid arrows in Fig. 5 (j) indicate lateral extension of the large crack that is caused by the similar stress concentration. The black dotted arrows $1-8$ in Fig. 5 (j) indicate eight hydrogen micropores that can also be confirmed in Fig. 5 (a). It is interesting to note that the pre-existing micropores exhibited characteristic predominant growth in the loading direction. 
Fig. 3 (a) - (d) also shows the magnified views of the interior of the material during deformation. Generally, void initiation caused by particle fracture occurs after the maximum load has been reached [1-3]. Fig. 3 (b) corresponds to its vicinity. Pre-existing hydrogen micropores are highlighted in red and yellow. Of these, the yellow pores coalesce and merge into a fracture surface later. At this stage these micropores are observed together with the initiation of microvoids (highlighted in dark blue). It should be noted that the hydrogen micropores are much larger than the microvoids. There are seven yellow micropores in this field of view, and they have already coalesced with neighbouring micropores at the stage shown in Fig. 3 (b). Particle A exhibits multiple fractures owing to its size and irregular shape, leading to the formation of several relatively coarse microvoids. The microvoids subsequently coalesced, and a crack originated from the hydrogen micropores in Fig. 3 (d). Although the number of microvoids increases more with loading than the number of hydrogen micropores, we can conclude that the pre-existing hydrogen micropores dominate the fracture process from a relatively early stage.

\section{Identification of fracture origins}

\subsection{Fracture trajectory analysis}

To quantitatively assess the role of the pre-existing micropores in relation to the entire fracture, we analysed the process by which a fracture surface is formed. The central portions of the fracture surfaces, where typically a dimpled appearance is observed, were extracted as the regions of interest for the fracture trajectory analysis, as shown in Fig. 6. We extracted 500,000 equally-spaced position 
coordinates from each fracture surface (i.e., one side) in the tomographic images, so that we could accurately reproduce the configuration of the fracture surfaces. Reproduced fracture surfaces for materials $\mathrm{LH}$ and $\mathrm{HH}$ are shown in Fig. 7. The sampling pitch is narrower than that of the 3D image (i.e., an isotropic voxel with a $0.5 \mu \mathrm{m}$ edge), providing reasonable reproducibility of the fracture surfaces that have significant fracture surface roughness. To estimate the subsequent fracture path in the image obtained before loading, these position coordinates were tracked backward in time from the fracture surface image toward the initial, pre-load state. All the dispersion particles embedded in the entire field of view (16,667 particles) were tracked during loading, as was described in Section 2.3. The physical displacements between neighbouring loading steps, of all the particles located within a search area, were used to predict the invisible trajectory for each fracture surface location. The search area is $22.2 \sim 29.7 \mu \mathrm{m}$, which was determined such that at least five particles were embedded in the area. To predict the invisible trajectory for each fracture surface location, scattered data interpolation was performed using radial basis functions. Radial basis functions can provide interpolants to function values given at arbitrarily positioned particle locations, providing excellent approximations of the underlying local displacement field. The Gaussian interpolation matrix was used for this purpose because of its smoothness and rapid decay.

4.2 The results of the fracture trajectory analysis

Figures 8 and 9 show the estimated fracture paths (yellow and blue lines for upper and lower fracture surfaces, respectively) in images obtained before and during loading. The fracture surfaces shown in Figs. 8 and 9 (d) are obliquely directed, with 
significant surface asperity. The estimated fracture paths in the image obtained before loading are, however, relatively flat, suggesting that the significant fracture surface roughness can be attributed to complex local deformation during the fracture process. It would appear in Figs. 8 and 9 (a) that the predicted fracture paths connect agglomerated particles. Since there is a tendency for many hydrogen micropores to form on particles in such regions [15], it is hard to assess the actual fracture mechanisms using these data alone. Accordingly, micropores that are located along the estimated fracture paths before loading have been identified and tracked chronologically to match them with dimple patterns on the fracture surfaces. Each dimple is a basic structural unit that corresponds to a single local fracture event.

Fig. 10 shows 3D fracture surface images. The regions highlighted in yellow in Fig. 10 originated from hydrogen micropores. These regions occupy a fractional area of about 41.5 and $39.0 \%$ of the entire fracture surfaces for materials $\mathrm{LH}$ and $\mathrm{HH}$, respectively. The characteristic effects' of the micropores in the two materials are not significantly different. It seems that the yellow regions are connected in a somewhat reticulate manner, while the fracture surface formed by particle damage fills the remaining spaces. This is consistent with the tendency toward prior micropore growth seen in Figs. 3 and 5, and supports the view that this growth dominates the entire ductile fracture process beyond the obtained fractional area values. The summary of the fracture trajectory analysis is shown in Table 1 in terms of the characteristics of micropores. Note that volume fraction of the fatal micropores that directly contributed to the ductile fracture was calculated over the search areas. The geometrical features of the fatal micropores are close to those of the whole micropores, the only notable difference being that local micropore volume fraction is more than double in the former 
case, implying that agglomerated micropores tend to serve as the initial trigger for ductile fracture.

\section{Validation of the hydrogen micropore mechanism ductile fracture}

It is reasonable to assume that there is a vacuum inside the microvoids, whereas pre-existing micropores are filled with hydrogen [15]. This implies that if pre-existing hydrogen micropores contribute to ductile fracture, hydrogen trapped in the micropores is instantaneously released from the specimen at the moment of rupture. Fig. 11 shows stress-strain curves in the tensile tests, together with hydrogen desorption curves. Gradual hydrogen release is observed (Fig. 11) during plastic deformation as a result of dislocation movement along the slip planes [13]. This is followed by a sharp hydrogen emission peak when the final rupture occurs, in both materials, strongly suggesting that pre-existing hydrogen micropores are located on the fracture surface. Given that the gas pressure in each micropore is in thermal equilibrium with the surface tension, we can expect $3.52 \times 10^{-7} \mathrm{~cm}^{3} / \mathrm{m}^{2}$ of hydrogen to be released from the micropores that have merged into the fracture surface in material $\mathrm{HH}$. However, only $2.24 \times 10^{-9} \mathrm{~cm}^{3} / \mathrm{m}^{2}$ of hydrogen was emitted during the final rupture. It seems most likely that the hydrogen stored in the micropores had already been desorbed during the heat treatments in the sample preparation process, or redistributed into the alloy due to the significant increase in dislocation density during tensile deformation [15].

\section{Industrial implications of the finding}


The number of pre-existing micropores described here is typical of, or somewhat less than, the number found in engineering aluminium alloys. It is therefore reasonable to infer that an identical fracture mechanism operates in other aluminium alloys, and even in other structural metals that contain supersaturated gas.

The current industrial processes used to control mechanical properties, which optimise the species, size and spatial distribution of dispersion particles, are based on the conventional fracture mechanism. However, we suggest that microstructural factors that have been largely disregarded, such as hydrogen content and the size and spatial distribution of micropores, dominate the mechanical properties of metallic materials. For example, metallic materials are subjected to high-temperature heat treatments, such as homogenisation and solution treatments, to eliminate solute segregation and coarse dispersion particles. It has been believed that long-term high temperature exposure is effective for this purpose unless other factors such as grain growth play a role. However, in the light of the finding reported here, such intense heat treatment must have the opposite effect on the mechanical properties, since hydrogen micropores grow readily during high temperature exposure.

For example, analytical expressions have been well developed for the kinetics of dissolution of particles in the surrounding matrix. According to Aaron et al. [27], the total time for dissolution under volume-diffusion control, $t_{\mathrm{D}}$, is expressed as $t_{\mathrm{D}}=R_{0}^{2} / \mathrm{k} D_{v}$, where $R_{0}$ is the initial radius of particles, $k$ is the supersaturation parameter, and $D_{v}$ is the volume-diffusion coefficient. Given that the majority of dispersion particles in the materials used are $\mathrm{Al}_{2} \mathrm{Cu}, t_{\mathrm{D}} \approx 18,996 \mathrm{sec}$ at $673 \mathrm{~K}$ and $487 \mathrm{sec}$ at $768 \mathrm{~K}$ for measured $R_{0}=1.7 \mu \mathrm{m}$ for material $\mathrm{HH}$, with $k=0.061(673 \mathrm{~K})$ or $0.147(768 \mathrm{~K})$ and $D_{v}$ for $\mathrm{Cu}$ in $\mathrm{Al}$. This implies that the homogenisation treatment applied in this study (673 K for $28.8 \mathrm{ks}$ ) 
might be reasonable, while the solution treatment at $768 \mathrm{~K}$ for $7.2 \mathrm{ks}$ is roughly 15 times longer than the time necessary to dissolve the $\mathrm{Al}_{2} \mathrm{Cu}$ particles. Since it has been proved that hydrogen micropores exhibit Ostwald ripening, micropore diameter varies proportionally with $t^{1 / 2}(t$ : time) [28]. Micropores therefore grow by 3.8 times during the unnecessary solution-treatment time, implying that there is a unique opportunity for mechanical property improvement through simply adopting a lower temperature and/or shorter time for the solution treatment. Although it has been claimed that interdendritic micropores in cast aluminium alloys do not completely close through extensive deformation by hot and cold rolling [18], reducing micropores by plastic working is also expected to lead to an effective method of improving mechanical properties. The discovery of the real fracture mechanism have, in this way, a major influence on the thermomechanical processes employed with metallic materials, from casting to the final product.

\section{Summary}

We have focused on high-density micropores filled with hydrogen in the aluminium alloy. We have clarified that high-density pre-existing micropores, which were formed during the production process, exhibit premature growth and coalescence under external loading, thereby inducing ductile fracture. The process is incidentally supplemented by the well-established ductile fracture mechanism based on particle damage. We have also obtained the conclusive evidence of the micropore mechanism by the observation of an instantaneous release of gas at failure during tensile loading. We can therefore conclude that the growth of micropores dominates ductile fracture in the 
case of the aluminium alloy. Since the material we used has a standard pore density, we can assume that an identical fracture mechanism operates in other aluminium alloys. the mechanical properties through homogenisation, may have entirely the opposite effect. This revelation will have a major impact on the engineering design of metals.

\section{Acknowledgements}

This work was partly undertaken with the support of a Grant-in-aid for Scientific Research from JSPS through subject No. 20246102. The synchrotron radiation experiments were performed with the approval of JASRI through proposal Nos. 2009B1131 and 2009A1315. The support provided by the Light Metal Educational Foundation to HT is also gratefully acknowledged. The authors thank Dr. Katsumi Koyama for analyzing the hydrogen content of the materials used. 


\section{References}

[1] S.H. Goods and L.M.Brown, Acta Metall.27 (1979) p.1.

[2] F.J.McClintock, Appl. Mech. 35 (1968) p.363.

[3] P.J.Thomason, Inst. Met. 96 (1968) p.360.

[4] R.M.Thomson, Physical Metallurgy Ch. 26 .In Elsevier, Amsterdam, 1996.

[5] T.L.Anderson, Fracture Mechanics Ch. 5.In CRC Press, Boca Raton, 1995.

[6] B.L.Bramfitt, R.C.Benn, C.R.Brinkman and G.F.Vander Voort, Optimization of Processing, Properties, and Service Performance Through Microstructural Control, ASTM STP979 1988;ASTM, Philadelphia.

[7] W.M.Garrison. Jr, J. Phys. Chem. Solids. 48 (1987) p.1035.

[8] J.P.Tanaka, C.A.Pampillo and J.R.Low. Jr, ASTM STP 463, American Society for Testing and Materials 1970, p.191.

[9] H.Toda, T. Kobayashi and A.Takahashi , Aluminum Trans.1.1(1999) p.109.

[10] M.F.Ashby, Phil. Mag. 14 (1966) p.1157.

[11] B.I.Edelson and W.M.Baldwin, Trans ASM.55 (1962) p.230.

[12] A.Koch, P.Cloetens , W.Ludwig, J.C.Labiche, B.Ferrand, in Proceedings of the Fifth International Conference on Inorganic Scintillators and Their Applications, M.V. Lomonosov, Ed. (Moscow State University, Moscow, 2000) p.157.

[13] J.Banhart, Advanced Tomographic Methods in Materials Research and Engineering. Oxford Univ Press, 2008.

[14] H. Toda, I. Sinclair, J.Y. Buffière, E. Maire, K. H. Khor, P. Gregson, T.Kobayashi, Acta Mater.52 (2004) p.1305.

[15] H.Toda , T.Hidaka ,M. Kobayashi, K.Uesugi, A.Takeichi, K. Horikawa, Acta 
Mater.57 (2009) p.2277.

[16] H.Toda, T. Yamaguchi, M.Nakazawa,Y. Aoki ,K. Uesugi, Y.Suzuki , M. Kobayashi . Mater. Trans. 51 (2010) p.1288.

[17] S.Masuda ,H. Toda, S.Aoyama,S. Orii,S. Ueda,M. Kobayashi, J. Japan Foundry Engng. Soc.81 (2009) p.312.

[18] D.E.Talbot, J. Inter. Metall. Rev.20 (1975) p.166.

[19] H.Toda, K. Minami, K. Koyama, K.Ichitani, M.Kobayashi, K.Uesugi, Y.Suzuki, Acta Mater. 57 (2009) p.4391.

[20] S.G. Lee, G.R. Patel, A.M.Gokhale, A.Sreeranganathan and M.F.Horstemeyer, Mater. Sci. Engng A.427 (2006) p.255.

[21] J.Y.Buffière, S.Savelli, P.H.Jouneau, E.Maire, R.Fougères, Mater. Sci. Engng A. 316 (2001) p.115.

[22] H.Toda, H.Oogo, K.Uesugi and M.Kobayashi , Mater. Trans 50(2009) p.2285.

[23] H.Oogo, H.Toda, K.Uesugi, Y.Suzuki and M.Kobayashi, J. Japan Institute of Light Metals.60 (2010) p.409.

[24] M.Kobayashi, H.Toda,Y. Kawai, T.Ohgaki, K.Uesugi, D.S.Wilkinson,T. Kobayashi , Y.Aoki and M.Nakazawa, Acta Mater.56(2008) p.2167.

[25] H.Toda , E. Maire, Y.Aoki and M.Kobayashi, J. Strain Analysis.46(2011) p.2911.

[26] G.Itoh, M. Kanno,Kinzoku .66 (1996) p.599.

[27] H.B.Aaron and G.R.Kolter , Metall. Trans.2(1971) p.393.

[28] G.W.Greenwood, A.Boltax, J. Nuclear Mater.5 (1962) p.234. 


\section{Caption list}

Fig. 1 Variations of the diameter and sphericity of micropores and particles in materials HH and LH.

Fig. 2 A series of 3D-rendered images of material $\mathrm{HH}$ during loading, representing the growth of pre-existing hydrogen micropores, together with the ordinary ductile fracture from particle damage. Particles are shown in light blue, and voids / micropores in red, in (a) - (g), whereas underlying aluminum is not displayed; (h) shows the corresponding outer contour of a fractured specimen.

Fig. 3 Magnified views of hydrogen pores (red), particles (light blue) and particle damage (dark blue), representing pre-existing hydrogen micropores that caused the final fracture (distinguished from the other micropores and highlighted in yellow) and their subsequent growth and coalescence behaviours. Note that only the microstructural features have been extracted; the underlying aluminum is not displayed.

Fig. 4 Stress-strain curve recorded during the in-situ tensile test of material HH. Note that tomographic scans were performed at the specified 10 loading steps.

Fig. 5 3D-perspective views of hydrogen micropores (shown in red), together with voids originating from particle damage in material $\mathrm{HH}$, representing the early growth and coalescence of the micropores, which is followed by the coalescence of micropores due to additional void formation in between. Note that only the micropores have been extracted; the underlying aluminum is not displayed.

Fig. 6 (a) and (c) are the SEM fractographs (lower fracture surface) of materials HH and LH, respectively; (b) and (d) are corresponding tomographic images.

Fig. 7 3D-perspective views of the fracture surface, which have been reconstructed by 
extracting 500,000 locations on each fracture surface and then connecting the fracture surface locations; (a) and (c) are those of material $\mathrm{HH}$, and (b) and (d) are those of material LH.

Fig. 8 Estimated fracture paths shown on a virtual tomographic cross section at each loading step, in material HH. Upper (yellow) and lower (blue) fracture surfaces have been tracked back toward the initial, pre-load state by utilizing local displacement fields expressed with radial basis functions that have been obtained by tracking particles.

Fig. 9 Estimated fracture paths shown on a virtual tomographic cross section at each loading step, in material LH. Upper (yellow) and lower (blue) fracture surfaces have been tracked back toward the initial, pre-load state by utilizing local displacement fields expressed with radial basis functions that have been obtained by tracking particles.

Fig. 10 3D-perspective views of the fracture surface, obtained with X-ray microtomography, representing dimple patterns originating from pre-existing hydrogen micropores (highlighted in yellow).

Fig. 11 Hydrogen desorption from specimens during tensile tests that have been performed under an ultra-high vacuum atmosphere. The amounts of hydrogen desorbed are expressed as ion current values. Note that abrupt increases in hydrogen desorption are observed in both of the materials upon the final fracture.

Table 1 Results of 3D quantitative image analysis for hydrogen micropores. 'Fatal pores' are those contributing to the formation of the fracture surface, which have been extracted by means of the fracture-path tracking. 


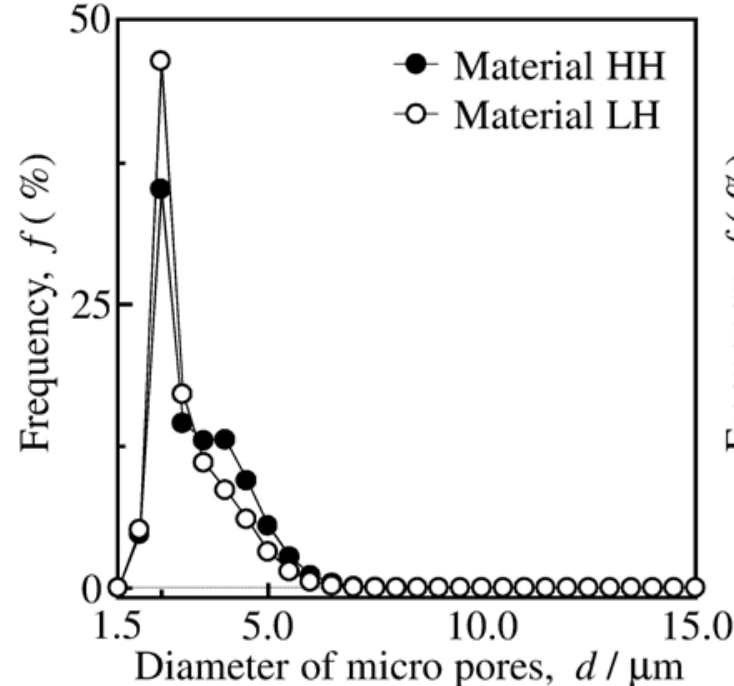

(a) Diameter

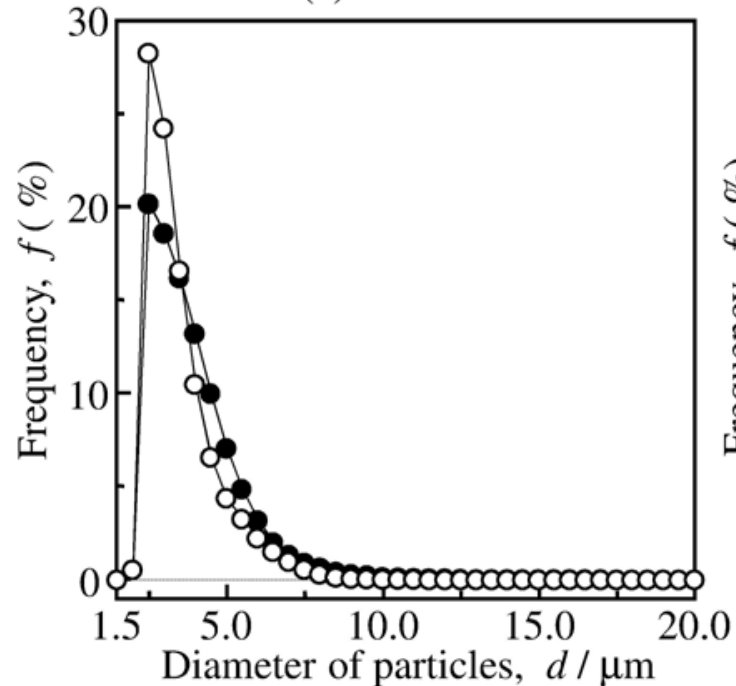

(c) Diameter

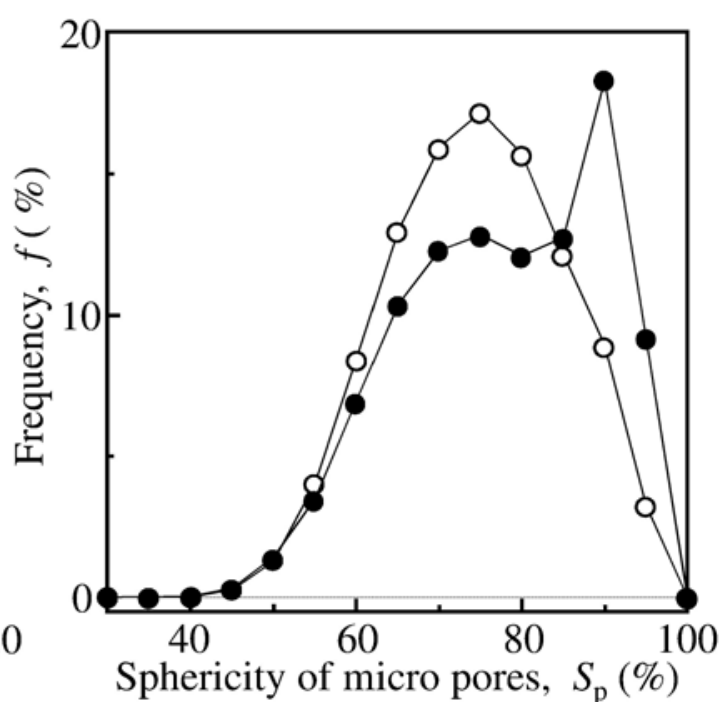

(b) Sphericity

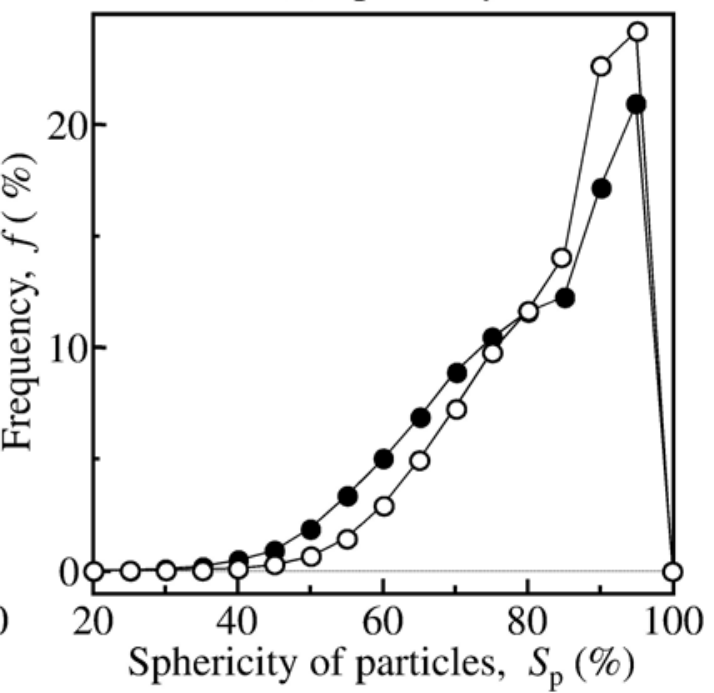

(d) Sphericity

Fig. 1 Variations of the diameter and sphericity of micropores and particles in materials HH and LH. 


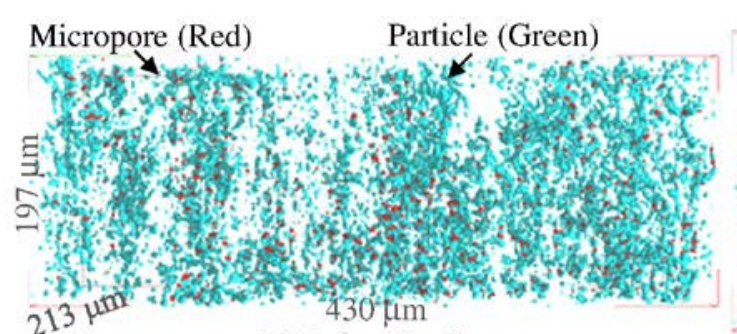

(a) Before loading

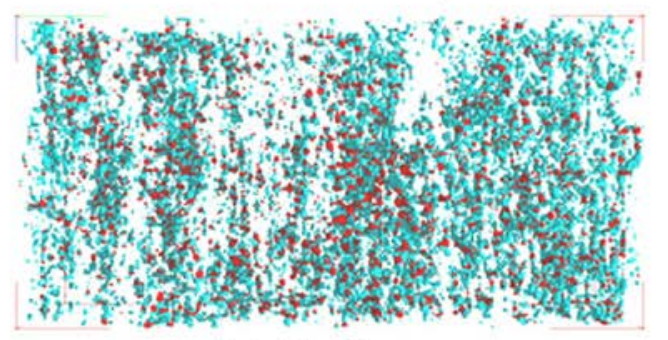

(c) 3rd loading step

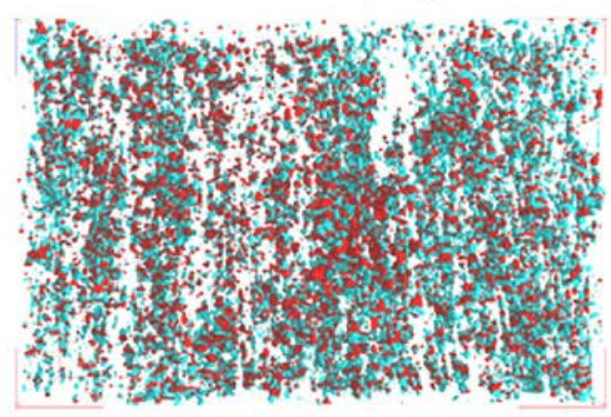

(e) 5 th loading step

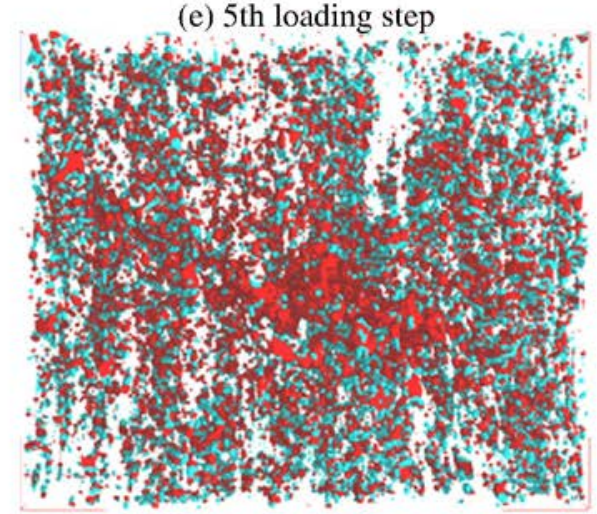

(g) 9th loading step

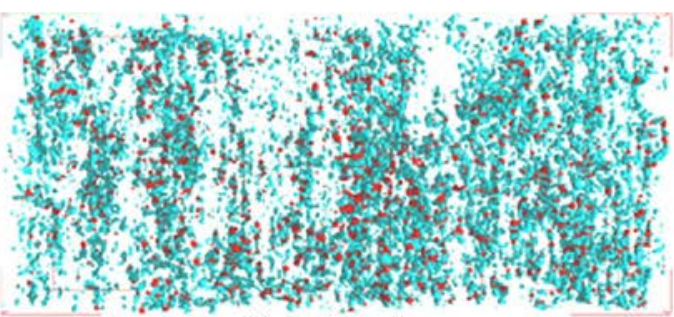

(b) 2nd loading step

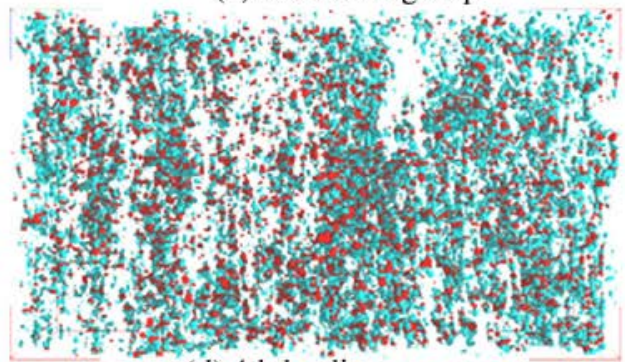

(d) 4th loading step

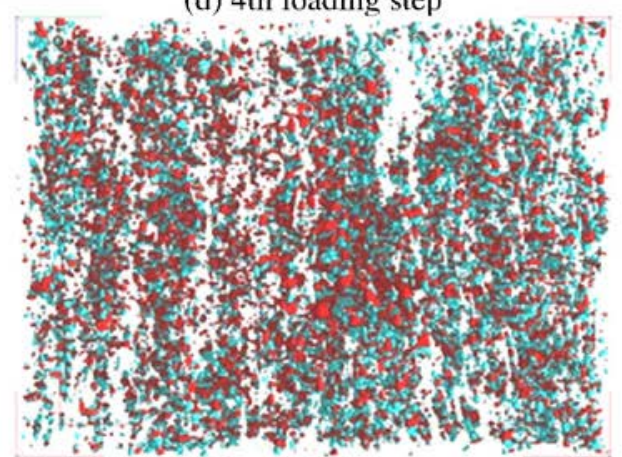

(f) 6th loading step

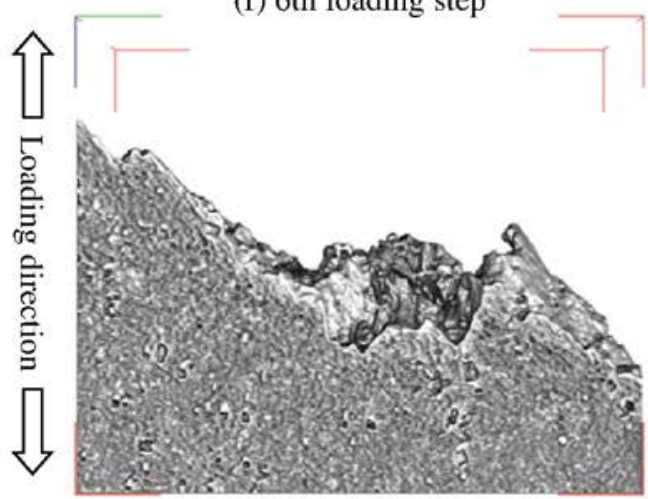

(h) Fracture surface

Fig. 2 A series of 3D-rendered images of material $\mathrm{HH}$ during loading, representing the growth of pre-existing hydrogen micropores, together with the ordinary ductile fracture from particle damage. Particles are shown in light blue, and voids / micropores in red, in (a) - (g), whereas underlying aluminum is not displayed; (h) shows the corresponding outer contour of a fractured specimen. 


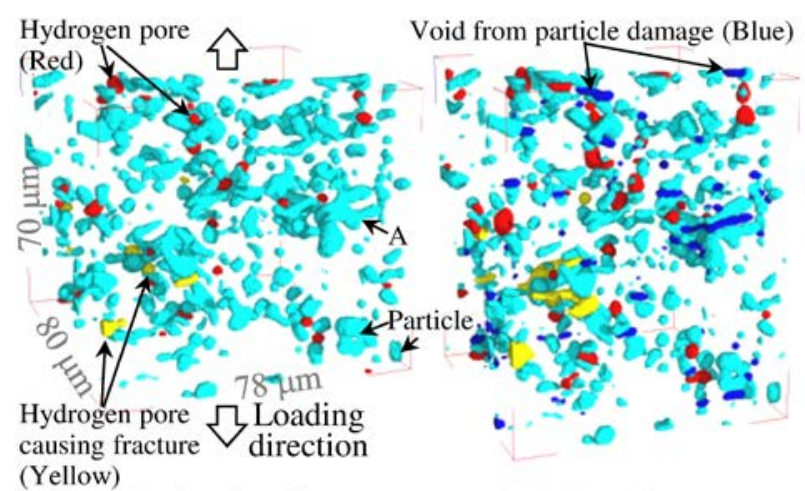

(a) Before loading (b) 3rd loading step

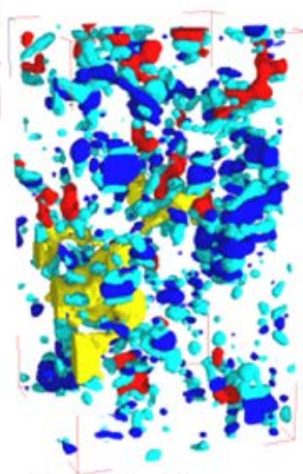

(c) 6th loading step

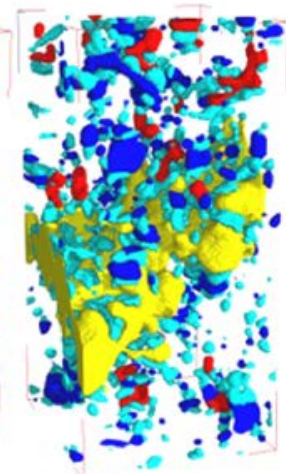

(d) 8th loading step

Fig. 3 Magnified views of hydrogen pores (red), particles (light blue) and particle damage (dark blue), representing pre-existing hydrogen micropores that caused the final fracture (distinguished from the other micropores and highlighted in yellow) and their subsequent growth and coalescence behaviours. Note that only the microstructural features have been extracted; the underlying aluminum is not displayed. 


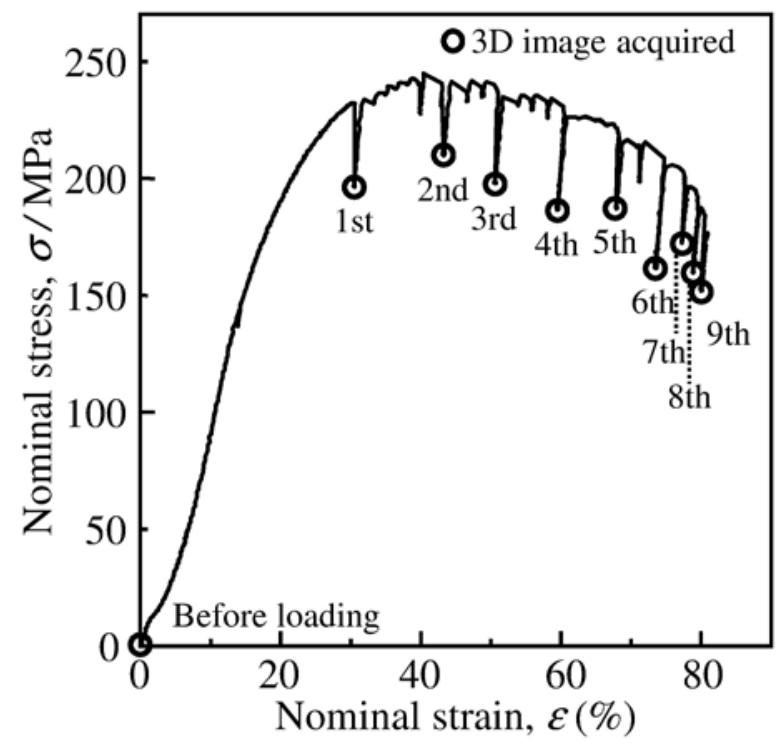

Fig. 4 Stress-strain curve recorded during the in-situ tensile test of material HH. Note that tomographic scans were performed at the specified 10 loading steps. 


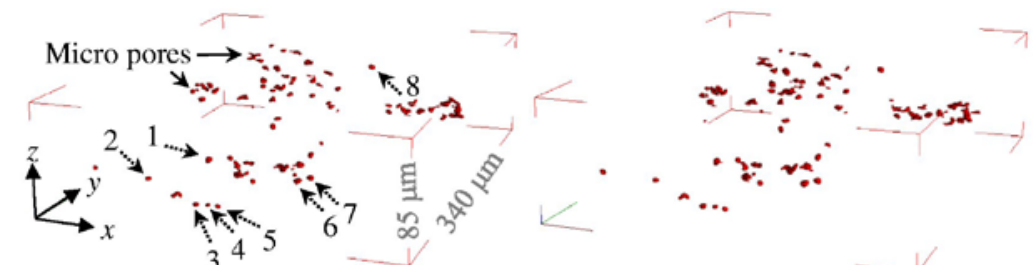

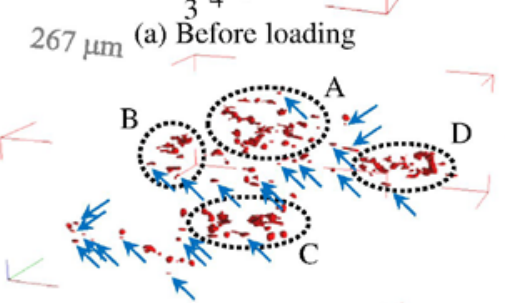

(c) 2nd loading step

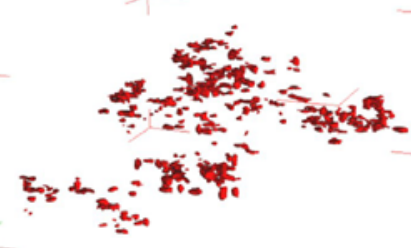

(e) 4th loading step

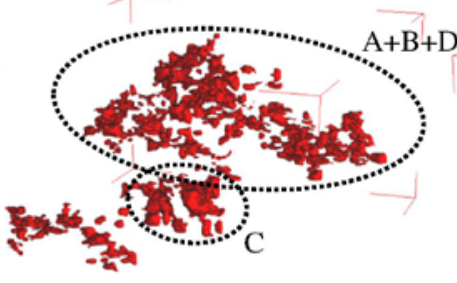

(b) 1st loading step

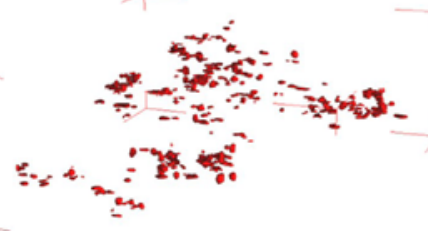

(d) 3rd loading step

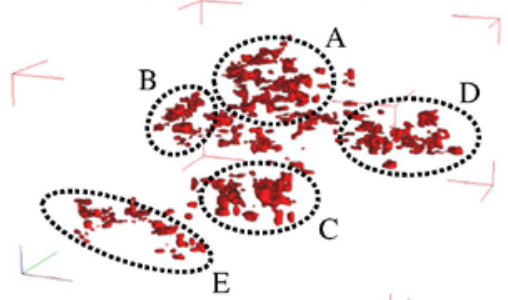

(f) 5 th loading step

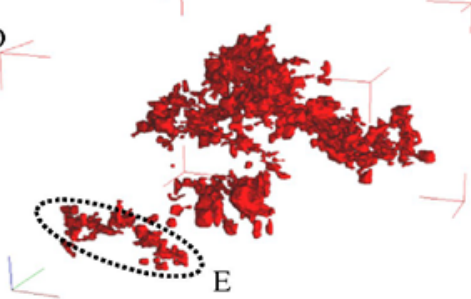

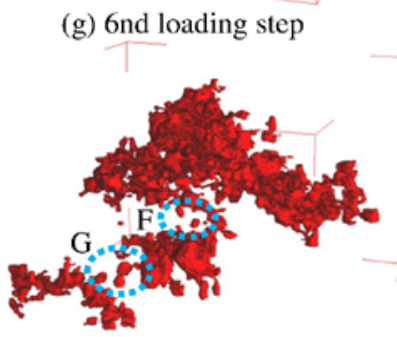

(i) 8th loading step (h) 7 th loading step

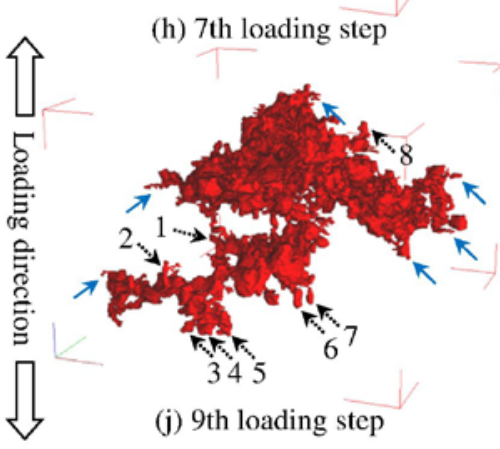

Fig. 5 3D-perspective views of hydrogen micropores (shown in red), together with voids originating from particle damage in material $\mathrm{HH}$, representing the early growth and coalescence of the micropores, which is followed by the coalescence of micropores due to additional void formation in between. Note that only the micropores have been extracted; the underlying aluminum is not displayed. 


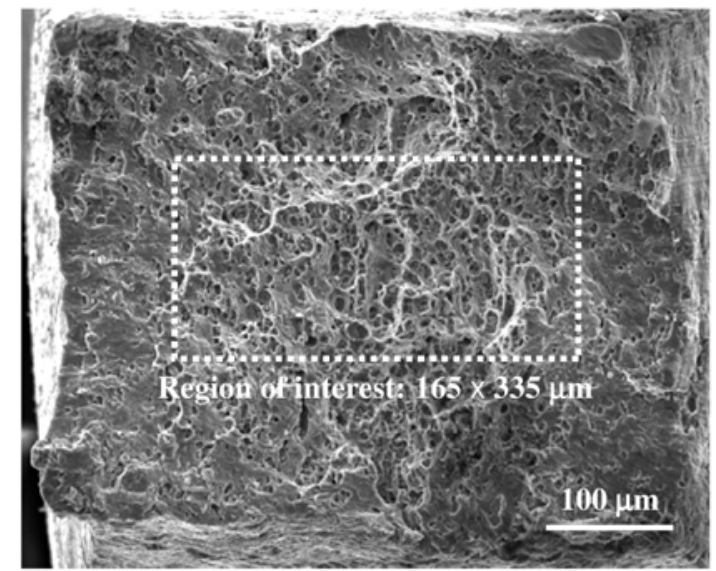

(a) SEM image (Material $\mathrm{HH})$

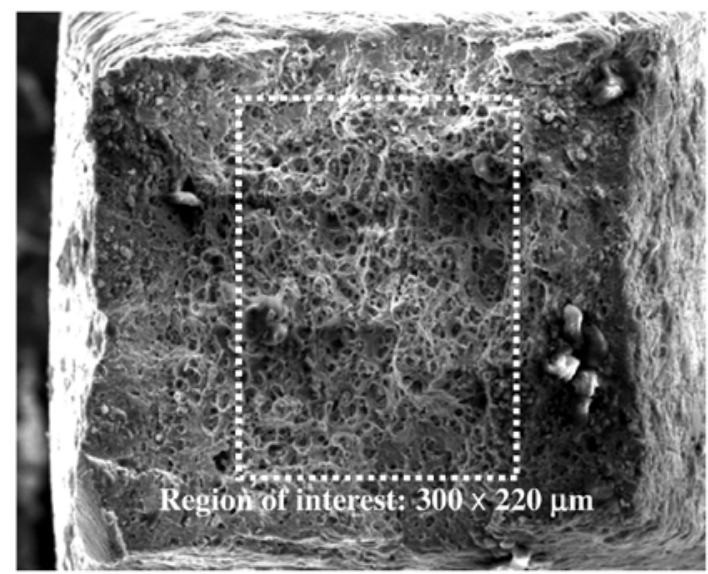

(c) SEM image (Material LH)

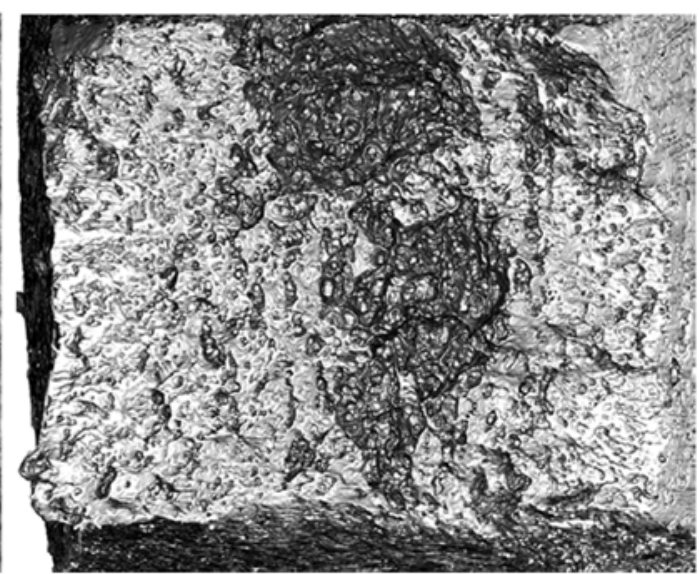

(b) Tomographic image (Material HH)

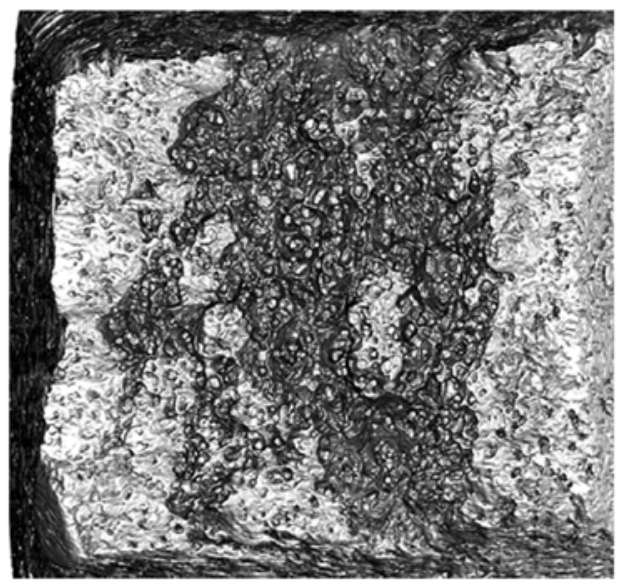

(d) Tomographic image (Material LH)

Fig. 6 (a) and (c) are the SEM fractographs (lower fracture surface) of materials HH and

LH, respectively; (b) and (d) are corresponding tomographic images. 

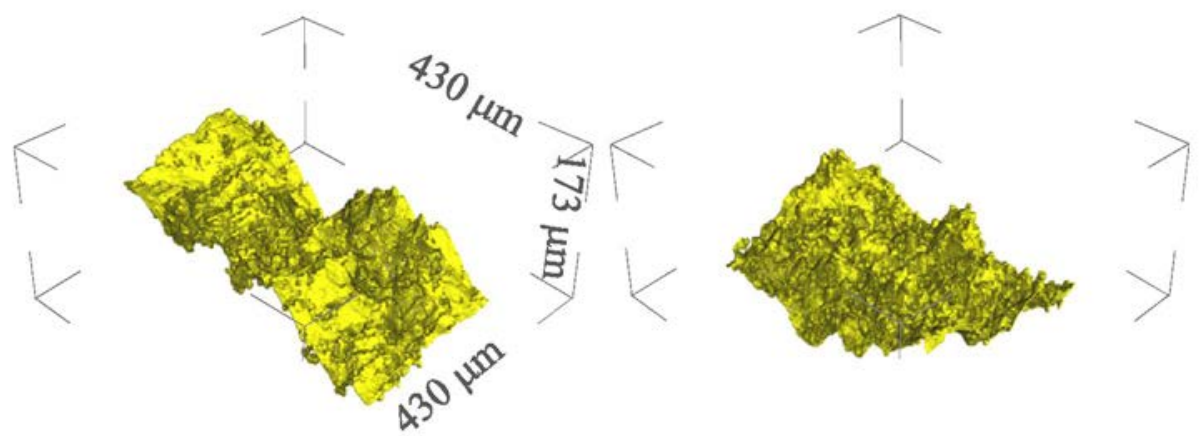

(a) Upper fracture surface $(\mathrm{HH})$

(b) Upper fracture surface (LH)
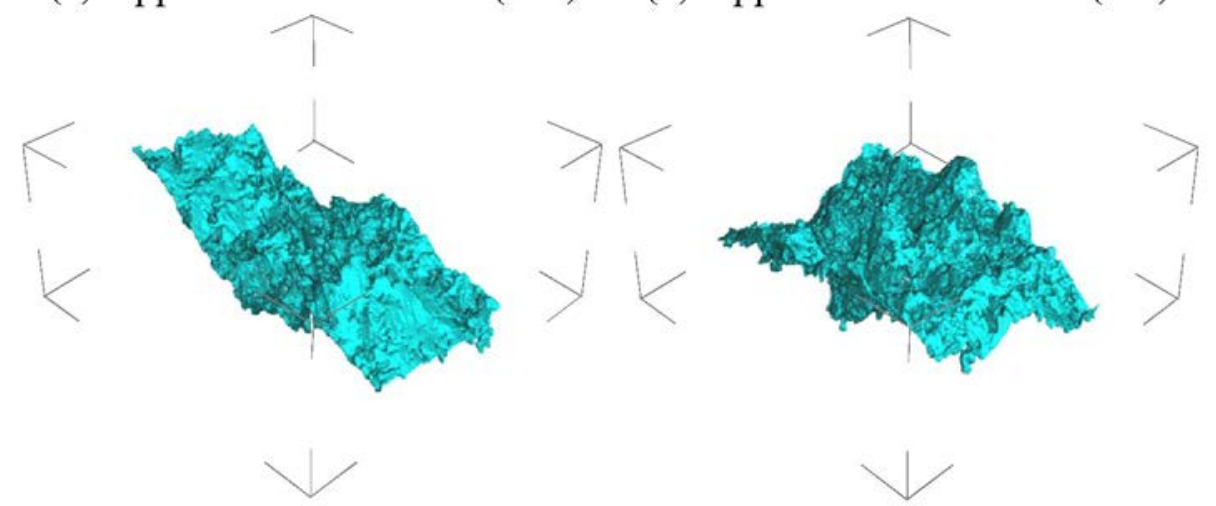

(c) Lower fracture surface $(\mathrm{HH})$

(d) Lower fracture surface (LH)

Fig. 7 3D-perspective views of the fracture surface, which have been reconstructed by extracting 500,000 locations on each fracture surface and then connecting the fracture surface locations; (a) and (c) are those of material $\mathrm{HH}$, and (b) and (d) are those of material LH. 


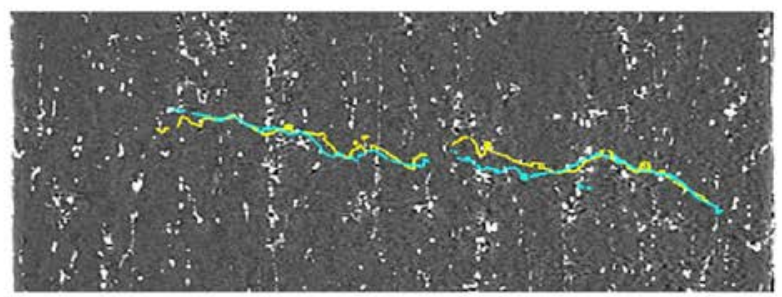

(a) Before loading

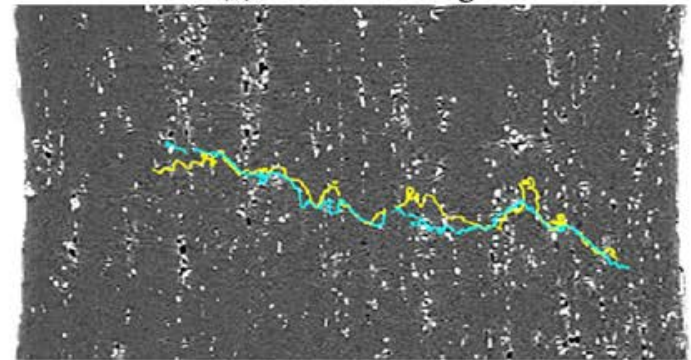

(b) 4th loading step

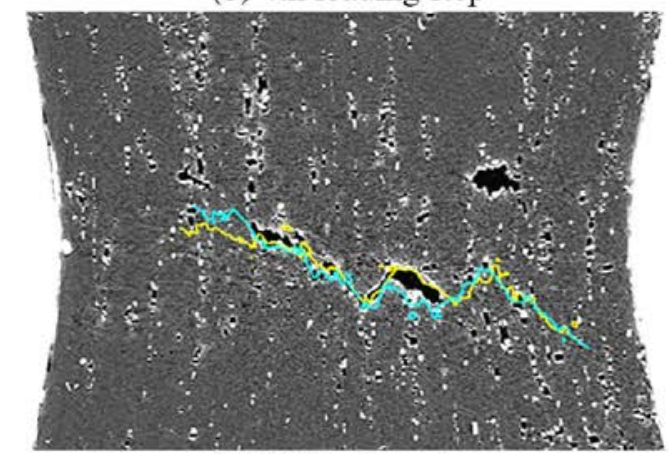

(c) 9th loading step

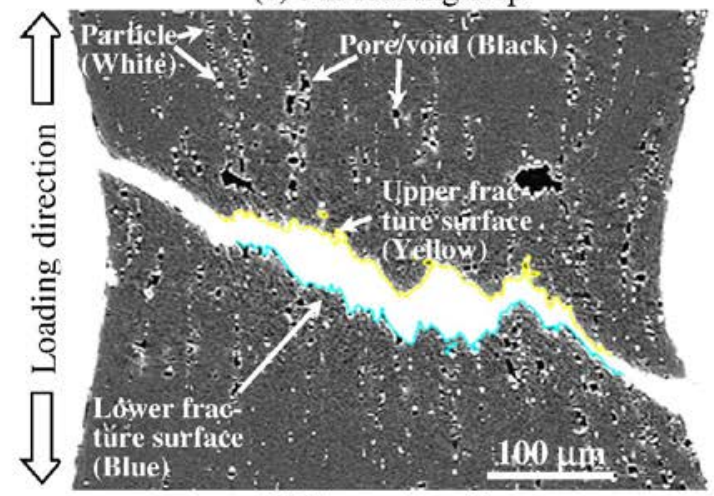

(d) Fracture surface

Fig. 8 Estimated fracture paths shown on a virtual tomographic cross section at each loading step, in material HH. Upper (yellow) and lower (blue) fracture surfaces have been tracked back toward the initial, pre-load state by utilizing local displacement fields expressed with radial basis functions that have been obtained by tracking particles. 


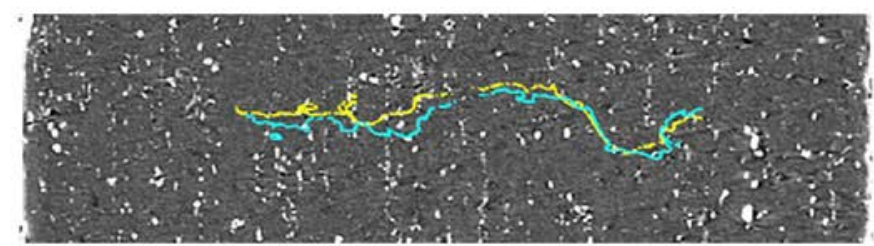

(a) Before loading

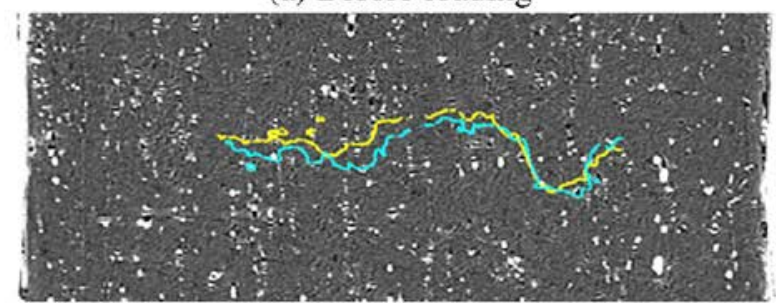

(b) 6th loading step

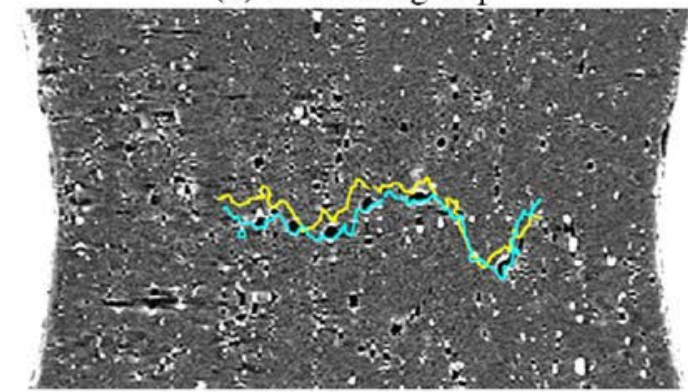

(c) 12th loading step

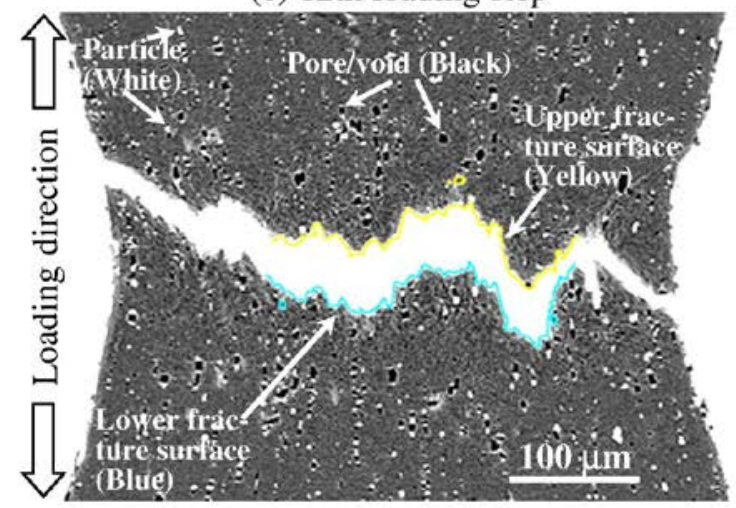

(d) Fracture surface

Fig. 9 Estimated fracture paths shown on a virtual tomographic cross section at each loading step, in material LH. Upper (yellow) and lower (blue) fracture surfaces have been tracked back toward the initial, pre-load state by utilizing local displacement fields expressed with radial basis functions that have been obtained by tracking particles. 

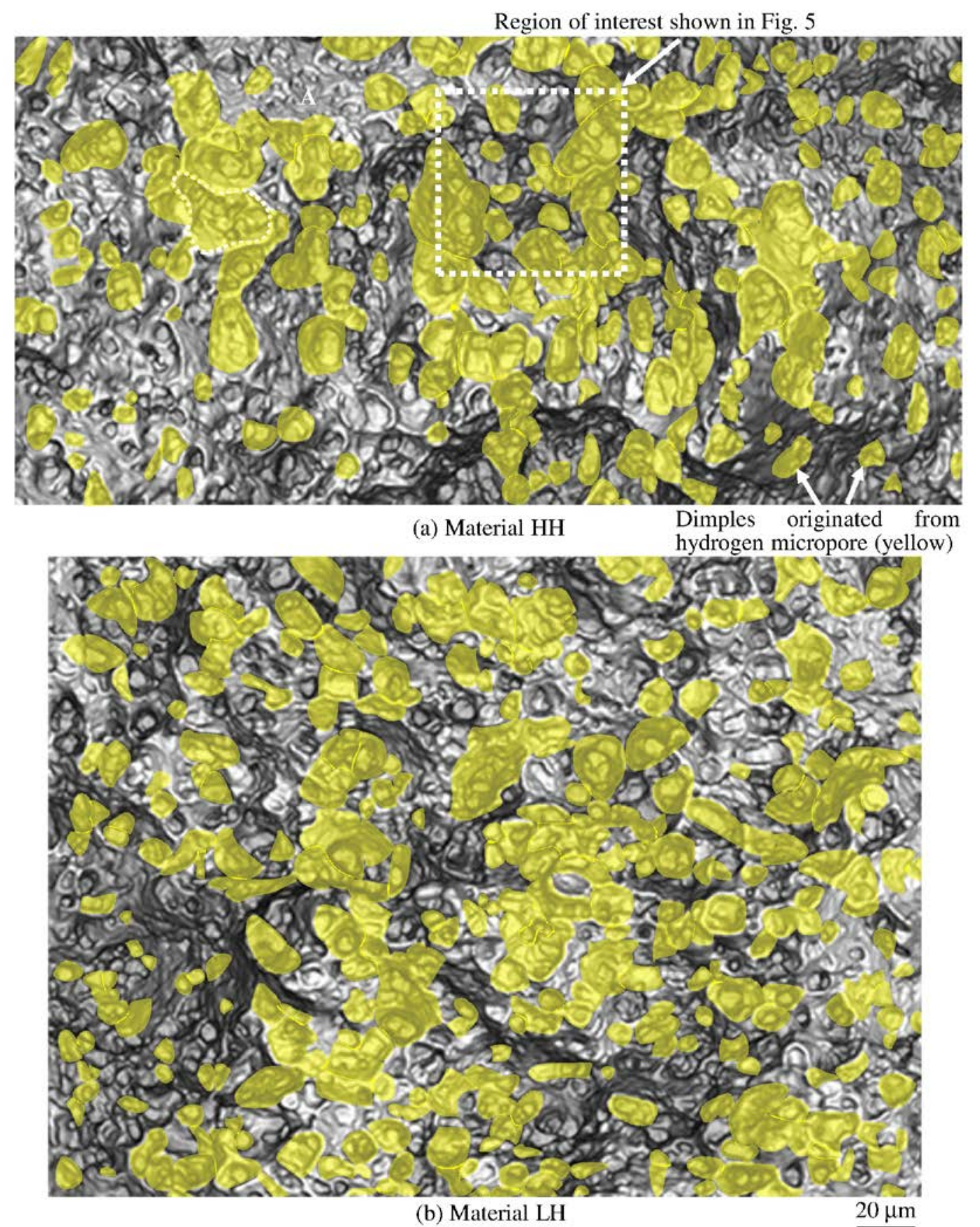

Fig. 10 3D-perspective views of the fracture surface, obtained with X-ray microtomography, representing dimple patterns originating from pre-existing hydrogen micropores (highlighted in yellow). 


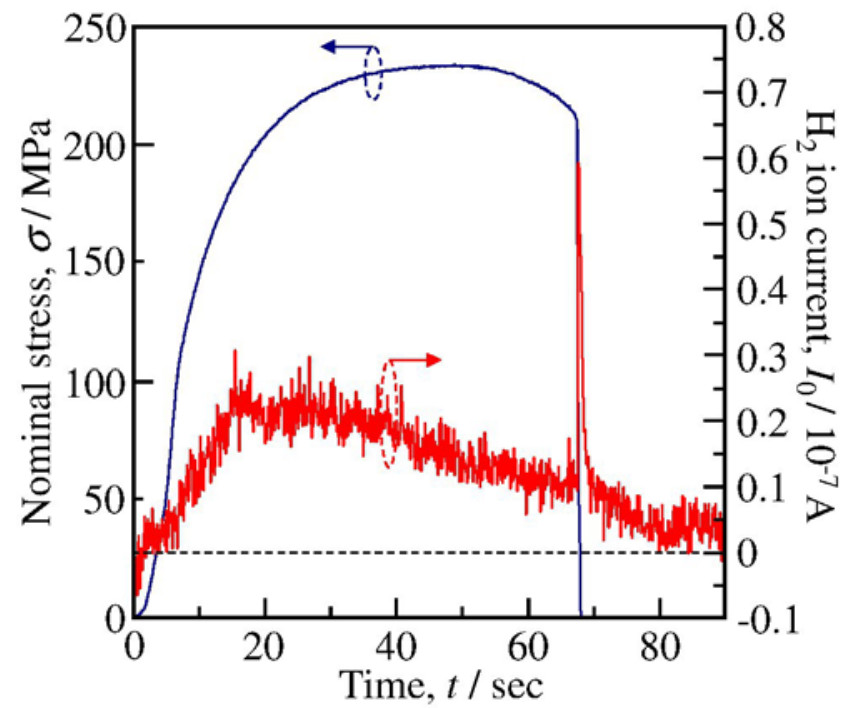

(a) Material $\mathrm{HH}$

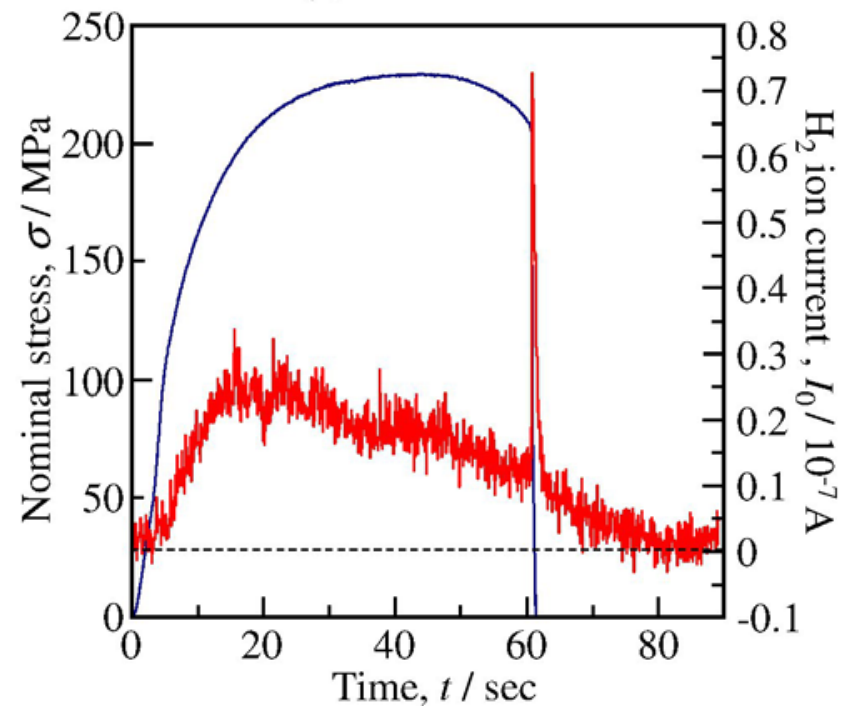

(b) Material LH

Fig. 11 Hydrogen desorption from specimens during tensile tests that have been performed under an ultra-high vacuum atmosphere. The amounts of hydrogen desorbed are expressed as ion current values. Note that abrupt increases in hydrogen desorption are observed in both of the materials upon the final fracture. 
Table 1 Results of 3D quantitative image analysis for hydrogen micropores. 'Fatal pores' are those contributing to the formation of the fracture surface, which have been extracted by means of the fracture-path tracking.

\begin{tabular}{clcc}
\hline \hline \multicolumn{1}{c}{ Properties } & & Material HH & Material LH \\
\hline \multirow{2}{*}{ Number of pores, $N_{\mathrm{p}}$} & Fatal pores & 658 & 820 \\
& Whole pores & 37,505 & 34,096 \\
\hline \multirow{2}{*}{ Average diameter, $d / \mu \mathrm{m}$} & Fatal pores & 2.8 & 2.6 \\
& Whole pores & 2.8 & 2.5 \\
\hline \multirow{2}{*}{ Average phericity, $S_{\mathrm{p}}(\%)$} & Fatal pores & 70.6 & 68.7 \\
& Whole pores & 69.4 & 69.0 \\
\hline \multirow{2}{*}{ Volume fraction, $V_{\mathrm{f}}(\%)$} & Fatal pores & 0.63 & 0.48 \\
& Whole pores & 0.27 & 0.19 \\
\hline
\end{tabular}

